\title{
How can push-off be preserved during use of an ankle foot orthosis in children with hemiplegia? A prospective controlled study
}

\author{
Kaat Desloovere ${ }^{\mathrm{a}, \mathrm{b}, *}$, Guy Molenaers ${ }^{\mathrm{a}, \mathrm{c}}$, Leen Van Gestel ${ }^{\mathrm{b}}$, Catherine Huenaerts ${ }^{\mathrm{a}}$, \\ Anja Van Campenhout ${ }^{\mathrm{a}, \mathrm{c}}$, Barbara Callewaert ${ }^{\mathrm{a}}$, Patricia Van de Walle ${ }^{\mathrm{a}}$, J. Seyler ${ }^{\mathrm{d}}$ \\ ${ }^{a}$ Clinical Motion Analysis Laboratory, CERM, University Hospital of Pellenberg (Leuven), KU-Leuven, Weligerveld 1, 3212 Pellenberg, Belgium \\ ${ }^{\mathrm{b}}$ Department of Rehabilitation Sciences, Faculty of Kinesiology and Rehabilitation Sciences, KU-Leuven, Belgium \\ ${ }^{\mathrm{c}}$ Department of Musculoskeletal Sciences, KU-Leuven, Belgium \\ ${ }^{\mathrm{d}}$ Centre of Technical Orthopaedics, University Hospital Pellenberg, Pellenberg, Belgium
}

Received 15 May 2006; accepted 15 May 2006

\begin{abstract}
Several studies indicated that walking with an ankle foot orthosis (AFO) impaired third rocker. The purpose of this study was to evaluate the effects of two types of orthoses, with similar goal settings, on gait, in a homogeneous group of children, using both barefoot and shoe walking as control conditions. Fifteen children with hemiplegia, aged between 4 and 10 years, received two types of individually tuned AFOs: common posterior leaf-spring (PLS) and Dual Carbon Fiber Spring AFO (CFO) (with carbon fibre at the dorsal part of the orthosis). Both orthoses were expected to prevent plantar flexion, thus improving first rocker, allowing dorsiflexion to improve second rocker, absorbing energy during second rocker, and returning it during the third rocker. The effect of the AFOs was studied using objective gait analysis, including 3D kinematics, and kinetics in four conditions: barefoot, shoes without AFO, and PLS and CFO combined with shoes.

Several gait parameters significantly changed in shoe walking compared to barefoot walking (cadence, ankle ROM and velocity, knee shock absorption, and knee angle in swing). The CFO produced a significantly larger ankle ROM and ankle velocity during push-off, and an increased plantar flexion moment and power generation at pre-swing compared to the PLS $(<0.01)$. The results of this study further support the findings of previous studies indicating that orthoses improve specific gait parameters compared to barefoot walking (velocity, step length, first and second ankle rocker, sagittal knee and hip ROM). However, compared to shoes, not all improvements were statistically significant. (C) 2006 Elsevier B.V. All rights reserved.
\end{abstract}

Keywords: Ankle Foot Orthosis; Hemiplegia; Gait; Push-off; Carbon Fiber

\section{Introduction}

Ankle Foot Orthoses (AFOs) are frequently prescribed for ambulatory children with Cerebral Palsy (CP) to improve their walking pattern. Since the first orthosis was moulded, clinical application and design variation of orthotics has rapidly expanded. Most frequently applied AFOs for children with CP are the solid ankle foot orthosis (SAFO), hinged AFO (HAFO), dynamic AFO (DAFO) and posterior leaf-spring (PLS). All these orthoses prevent plantar flexion motion but the amount of dorsiflexion allowed depends on the specific

\footnotetext{
* Corresponding author. Tel.: +32 163380 09; fax: +32 16338012 .

E-mail address: kaat.desloovere@uz.kuleuven.ac.be (K. Desloovere).
}

type. Adequately tuned AFOs have been shown to successfully correct the first and second ankle rocker. However, their effect on the third rocker remains unclear [1-9].

Several studies indicate that walking with orthoses impairs the third rocker. A decreased push-off was found when children walked with HAFO, SAFO, DAFO, or PLS compared to barefoot or shoe walking $[5,6,8]$. However, the key question on the third rocker for the past few years has been whether the PLS can help to improve push-off or not. As the PLS is deformed into dorsiflexion during first and second rocker dynamic energy is absorbed, which can be unleashed during third rocker to assist push-off. Ounpuu et al. examined 19 children with unilateral and 12 with bilateral involvement, and compared barefoot walking to 
walking with PLS. No evidence was found indicating a spring-like function of the PLS during third rocker. Unfortunately the effects of the PLS were not compared to those of the rigid AFO [8]. Similar results were confirmed in the study by Buckon et al. [3].

There are several general shortcomings in recent literature on AFOs. First of all, there is lack of comparative studies on different types of orthoses, aiming at the same treatment goals. Studies are often carried out comparing different types of AFOs irrespective of their treatment goal [3,5,7,10-14]. It would be meaningful to compare orthoses prescribed for the same indications within a homogeneous group of patients. Another problem concerns the sets of objective data used for further analysis, which are often insufficient, allowing only a limited evaluation of AFOs [3,5,6-8,10,11,15,16]. Furthermore, studies often lack appropriate control groups and/or control conditions. Comparing barefoot and shoe walking comprises a first important control. Finally, when reviewing the literature, the reader is often confronted with contradictions in reported effects of certain AFOs on gait $[3-5,17,18]$.

A prospective study was set up to evaluate the effect of two types of orthoses, with similar goal settings, on gait, in a homogeneous group of children with hemiplegia, using both barefoot and shoe walking as control conditions. The aim of both orthoses was to prevent plantar flexion, thus improving the first ankle rocker, to allow dorsiflexion in order to improve the second rocker, and to absorb energy during second rocker in order to return it during the third ankle rocker.

\section{Methods}

\subsection{Subjects and materials}

Fifteen children diagnosed with hemiplegia received two types of individually tuned flexible AFOs: the common PLS and the Dual Carbon Fibre Spring ${ }^{\circledR}$ AFO (CFO). All children were selected at the multidisciplinary clinic for children with CP (at the University Hospital of Pellenberg). The inclusion criteria for enrolment in this study were: (1) diagnosis of spastic hemiplegia, (2) age between 4 and 10 years, (3) no Botulinum toxin-A treatment within 6 months from evaluation time, (4) adequate cooperation of the child, and (5) no previous orthopaedic surgery. The mean age was 5.86 years $( \pm 1.76)$, eight children had right, and seven children had left side involvement. All participants were informed of the nature of the study and their parents gave informed consent. All children were familiar with the use of AFOs and had been wearing them for at least $50 \%$ of time as part of their treatment.

At the time of the study, the two types of orthoses were moulded and tuned, based on the children's specific characteristics. This was done by the multidisciplinary team based on clinical examination and gait analysis. All children alternated between the use of both AFOs for at least 3 weeks before evaluation.

The flexible posterior leaf-springs (PLS) extended proximally to just below the neck of the fibula. Distally it included a footplate that extended along the length of the plantar surface of the foot to the tips of the toes (Fig. 1). They were secured with an upper strap across the anterior aspect of the proximal tibia and trimmed posterior to the ankle malleoli to allow sufficient flexibility towards dorsiflexion. The goal was to pre-position the foot for heel contact, allow dorsiflexion during the second rocker, promote push-off and achieve foot clearance in swing.

The Dual Carbon Fibre Spring AFO ${ }^{\circledR}$ (CFO) configuration resembled the PLS, except for the dorsal part which was cut into two parts (Fig. 2). A carbon L-shaped plate consisting of two carbon springs (Ossur paediatric spring ${ }^{\mathbb{R}}$ ), spanned the gap. The Ossur paediatric spring ${ }^{\circledR}$ was made from a combination of carbon and kevlar fibres pre-impregnated with

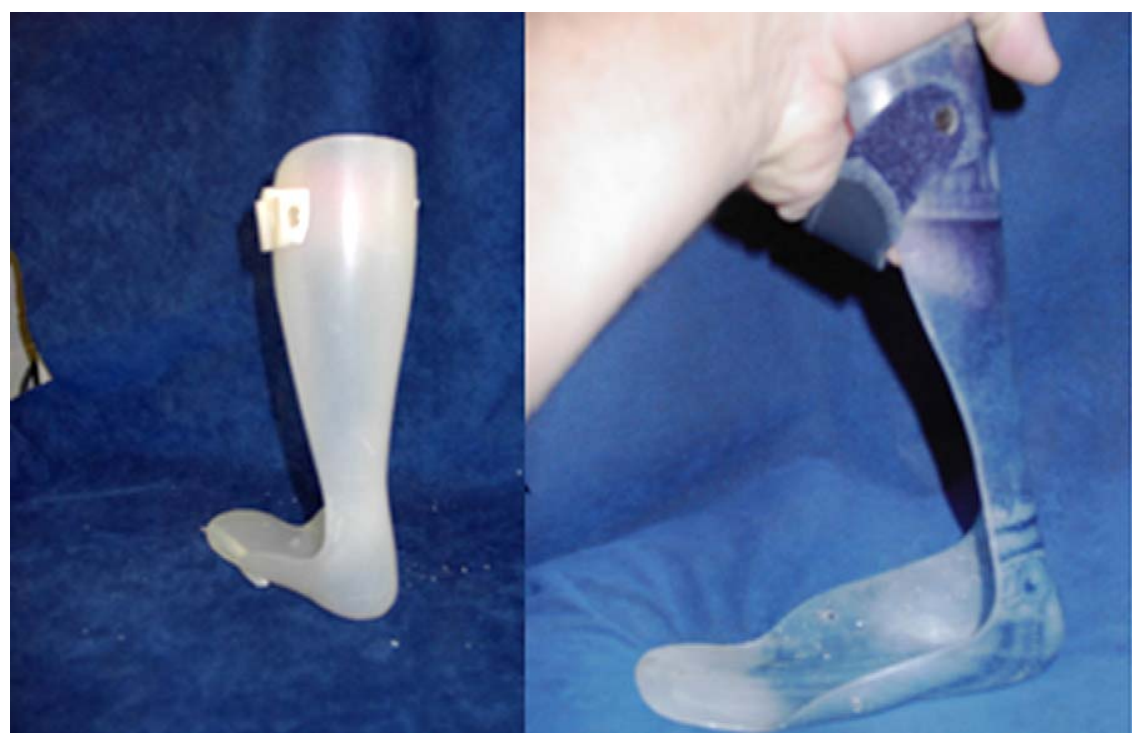

Fig. 1. Flexible posterior leaf-spring (PLS). 


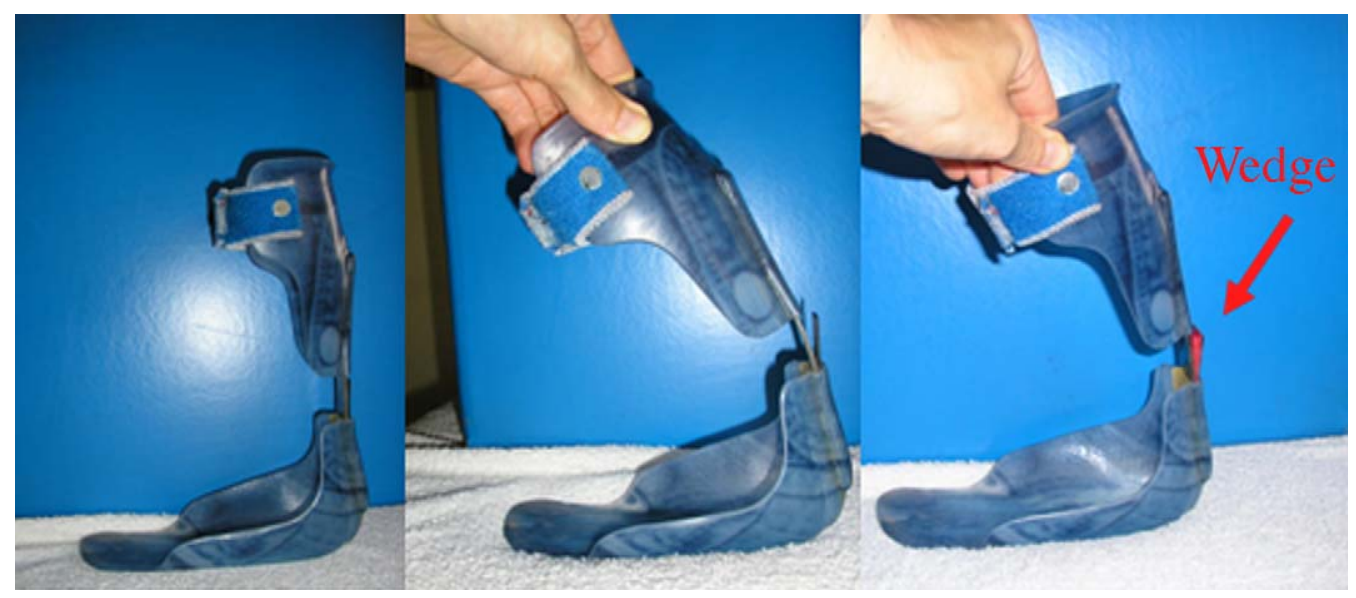

Fig. 2. Dual Carbon Fiber Spring AFO (CFO).

epoxy resin. The design of the spring allowed for good durability, excellent stiffness to weight ratio, and consistent performance. The spring also provided good energy return characteristics. The construct included two springs connected together distally to provide greater resistance to plantarflexion than dorsiflexion. The amount of overlap (50\% in this study) determined the orthosis' flexibility and the restriction towards plantarflexion. The use of the overlapped carbon springs also allowed for fine-tuning of the forward thrust. A small wedge (with different possible angles) could be inserted between the carbon springs enabling further fine-tuning without having to completely remould the CFO (Fig. 2). Different types of carbon material could be used for the springs: type 1 through three displayed progressively more resistance to bending forces. The applied carbon springs in this study were all type 1 , and all CFOs were tuned without additional wedge between the carbon springs.

\subsection{Study design}

Children always started walking barefoot, after which walking trials with shoes only and with PLS and CFO combined with shoes followed at random order.

Both the PLS and CFO were identically tuned and worn with the same shoes. Orthoses were applied bilaterally. Bilateral use of AFOs is standard practice for children with hemiplegia in our multidisciplinary team, and is aimed to promote symmetry by equalising the amount of power generation at both limbs.

\subsection{Test procedure}

Prior to gait analysis, standard anthropometric data were collected. Body height, weight, and bimalleolar distance were re-measured for every walking condition. Patients walked on a 10-m walkway at a self-selected speed. Kinematic measurements were collected using an eight-camera VICON system (612 data capturing system measuring at $120 \mathrm{~Hz}$, with lower limb PlugInGait marker set, VICON, Oxford Metrics,
Oxford, UK). Three force plates (Advanced Mechanical Technology Inc., Watertown, MA) were embedded in the walkway for force registration. Surface EMG data were collected on eight lower extremity muscle groups, using a 16 channel K-Lab EMG system (Biometrics, the Netherlands). Workstation and Polygon software (Oxford Metrics, Oxford, UK) were used to define the gait cycles, to determine the spatio-temporal parameters, and to estimate the joint angles and internal moments and powers (normalised for body mass). Only the kinematic and kinetic data of three trials of the involved side were used for further analysis in this study.

After barefoot walking, the retroreflective markers had to be repositioned on the shoes. Members of the multidisciplinary team rigorously controlled the strict replacement of the foot markers. In between the different orthoses walking conditions, the markers on the shoes were not replaced, to avoid additional variability.

\subsection{Data reduction}

In this study, we selected a set of 52 gait parameters from the kinematic and kinetic data. These were discrete values of joint angles, moments and power at specific points in the gait cycle, which were determined for three randomly selected gait trials of the involved side, per subject, and averaged. All selected parameters were defined based on a study of the literature [19-25] and based on the routine gait analysis protocol used at the Pellenberg Clinical Motion Analysis Laboratory (Leuven, Belgium). These parameters are presented in the first column of Table 1. The continuous trace (across one gait cycle) of the joint angles, moments and power of the three selected trials per subject were also studied.

\subsection{Statistical analysis}

Results of the study were compared to normal data of a group of healthy children ( $n=51$, age $=3-11$ years $)$. To exclude the effect of outliners in a limited test group, 
Table 1

Mean and interquartile range (IQR) for gait parameters of the four walking conditions $(N=15)$, along with the mean values with standard deviation (S.D.) of a normal control group of 51 children of 3-11 years of age, and $P$-values of the wilcoxon signed rank tests of three sets of comparisons of walking conditions

\begin{tabular}{|c|c|c|c|c|c|c|c|c|c|c|c|}
\hline \multirow[t]{2}{*}{ Parameter description } & \multicolumn{2}{|l|}{$\underline{B a r e f o o t}$} & \multicolumn{2}{|l|}{ Shoes } & \multicolumn{2}{|l|}{ PLS } & \multicolumn{2}{|l|}{$\mathrm{CFO}$} & \multicolumn{2}{|l|}{ Normal } & \multirow[b]{2}{*}{ B- } \\
\hline & Median & IQR & Median & IQR & Median & IQR & Median & IQR & Mean & S.D. & \\
\hline \multicolumn{12}{|l|}{ Spatio-temporal } \\
\hline Walking velocity (m/s) & 1.12 & 0.25 & 1.18 & 0.19 & 1.23 & 0.33 & 1.21 & 0.22 & 1.17 & 0.18 & \\
\hline Cadence (steps/min) & 142.30 & 14.00 & 130.50 & 10.50 & 130.50 & 19.50 & 131.50 & 12.50 & 139.00 & 22.10 & *** \\
\hline Step length $(\mathrm{m})$ & 0.48 & 0.12 & 0.50 & 0.09 & 0.58 & 0.11 & 0.55 & 0.09 & 0.50 & 0.09 & * \\
\hline $\begin{array}{l}\text { Timing toe-off ( } \% \text { of } \\
\text { the gait cycle) }\end{array}$ & 57.15 & 2.25 & 58.55 & 2.30 & 57.90 & 2.5 & 58.20 & 3.20 & 57.60 & 2.10 & * \\
\hline \multicolumn{12}{|l|}{ Ankle } \\
\hline Angle at initial contact $\left(^{\circ}\right)$ & -5.04 & 6.69 & -4.76 & 5.42 & 1.82 & 7.46 & 1.37 & 6.83 & 5.50 & 3.20 & \\
\hline $\begin{array}{l}\text { Range of motion during } \\
\text { push-off }\left({ }^{\circ}\right)\end{array}$ & 24.74 & 6.78 & 29.17 & 13.39 & 12.09 & 3.91 & 16.17 & 4.39 & 28.40 & 4.20 & \\
\hline $\begin{array}{l}\text { Timing of max dorsiflexion } \\
\text { in stance }(\%)\end{array}$ & 44.67 & 11.00 & 48.67 & 6.67 & 48.67 & 4.17 & 49.33 & 4.33 & 44.00 & 3.00 & * \\
\hline Max dorsiflexion in stance $\left(^{\circ}\right)$ & 10.14 & 8.56 & 15.13 & 5.25 & 11.90 & 8.99 & 14.29 & 9.32 & 14.00 & 5.10 & * \\
\hline Angle at mid-swing $\left(^{\circ}\right)$ & -4.56 & 7.52 & -6.23 & 5.89 & 0.69 & 5.08 & 1.15 & 7.71 & -2.10 & 4.50 & $*$ \\
\hline $\begin{array}{l}\text { Mean foot progression angle } \\
\text { in stance }\left(^{\circ}\right)\end{array}$ & -7.99 & 11.94 & -3.64 & 13.87 & -4.52 & 16.14 & -4.63 & 14.98 & -5.10 & 8.30 & * \\
\hline $\begin{array}{l}\text { Ankle moment at the end of } \\
\text { loading response }(\mathrm{Nm} / \mathrm{kg})\end{array}$ & 0.54 & 0.60 & 0.50 & 0.46 & 0.10 & 0.31 & 0.32 & 0.47 & 0.20 & 0.15 & \\
\hline $\begin{array}{l}\text { Max plantarflexion moment } \\
\text { in mid-stance }(\mathrm{Nm} / \mathrm{kg})\end{array}$ & 0.76 & 0.68 & 0.71 & 0.49 & 0.71 & 0.50 & 0.74 & 0.37 & 0.70 & 0.20 & \\
\hline $\begin{array}{l}\text { Max plantarflexion moment } \\
\text { in pre-swing }(\mathrm{Nm} / \mathrm{kg})\end{array}$ & 1.01 & 0.31 & 1.05 & 0.31 & 1.17 & 0.26 & 1.17 & 0.20 & 1.40 & 0.29 & \\
\hline $\begin{array}{l}\text { Max power absorption in } \\
\text { loading response (Al) } \\
(\mathrm{W} / \mathrm{kg})\end{array}$ & -1.04 & 0.90 & -1.46 & 1.21 & -0.78 & 0.56 & -0.92 & 0.53 & -0.60 & 0.40 & * \\
\hline $\begin{array}{l}\text { Max power generation in } \\
\text { pre-swing (A2) }(\mathrm{W} / \mathrm{kg})\end{array}$ & 2.02 & 1.00 & 1.74 & 1.04 & 1.46 & 0.35 & 1.68 & 0.99 & 2.90 & 1.10 & * \\
\hline $\begin{array}{l}\text { Angular velocity at toe-off } \\
(\mathrm{rad} / \mathrm{s})\end{array}$ & -3.64 & 1.28 & -5.00 & 2.59 & -1.31 & 1.13 & -1.88 & 1.10 & -5.10 & 1.03 & * \\
\hline \multicolumn{12}{|l|}{ Knee } \\
\hline Angle at initial contact $\left(^{\circ}\right)$ & 11.86 & 7.48 & 10.91 & 11.06 & 8.47 & 13.05 & 12.13 & 12.09 & 4.93 & 5.50 & \\
\hline max flexion in stance $\left({ }^{\circ}\right)$ & 18.41 & 9.47 & 23.04 & 13.72 & 18.40 & 10.29 & 20.51 & 11.11 & 16.40 & 7.40 & \\
\hline $\begin{array}{l}\text { Range of motion during } \\
\text { shock absorption }\left(^{\circ}\right)\end{array}$ & 6.20 & 6.67 & 12.13 & 12.04 & 9.93 & 9.11 & 10.11 & 9.38 & 13.20 & 6.40 & \\
\hline Max extension in stance $\left(^{\circ}\right)$ & -4.12 & 10.13 & -3.23 & 8.96 & -6.80 & 25.31 & -3.38 & 8.54 & 1.30 & 5.30 & \\
\hline Max flexion in swing ()$^{\circ}$ & 59.96 & 8.69 & 64.62 & 6.94 & 64.22 & 8.45 & 63.76 & 13.90 & 61.10 & 7.10 & \\
\hline $\begin{array}{l}\text { Timing of peak flexion in } \\
\text { swing relative to } \\
\text { toe-off }(\%)\end{array}$ & 16.52 & 2.03 & 15.68 & 3.10 & 14.82 & 2.15 & 14.80 & 3.18 & 14.60 & 1.80 & \\
\hline Max flexion in swing $\left(^{\circ}\right)$ & 73.00 & 1.67 & 74.67 & 3.67 & 72.67 & 1.67 & 73.00 & 3.0 & 61.10 & 7.00 & \\
\hline Flexion velocity at toe-off & 6.84 & 1.69 & 6.69 & 1.26 & 7.48 & 1.43 & 6.88 & 1.67 & 6.00 & 0.60 & \\
\hline
\end{tabular}

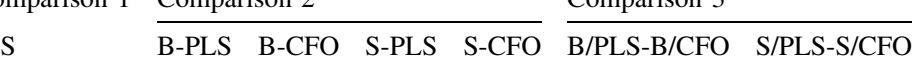

patio-temporal

the gait cycle)

Angle at initial contact $\left(^{\circ}\right)$

tion during

in stance (\%)

Angle at mid-swing $\left({ }^{\circ}\right)$

in stance $\left({ }^{\circ}\right)$

ax plantarflexion moment

in pre-swing $(\mathrm{Nm} / \mathrm{kg})$

oading response (Al)

ax power generation in

gular velocity at toe-off

Angle at initial contact $\left({ }^{\circ}\right)$

Range of motion during

shock absorption (

ax extension in stance (

exion velocity at toe-off

$6.84 \quad 1.69$

$(\mathrm{rad} / \mathrm{s})$ 


\begin{tabular}{|c|c|c|c|c|c|c|c|c|c|c|c|c|c|c|c|c|c|}
\hline \multirow[t]{2}{*}{ Parameter description } & \multicolumn{2}{|l|}{ Barefoot } & \multicolumn{2}{|l|}{ Shoes } & \multicolumn{2}{|l|}{ PLS } & \multicolumn{2}{|l|}{$\mathrm{CFO}$} & \multicolumn{2}{|l|}{ Normal } & \multirow{2}{*}{$\begin{array}{l}\text { Comparison } 1 \\
\text { B-S }\end{array}$} & \multicolumn{4}{|c|}{ Comparison 2} & \multicolumn{2}{|l|}{ Comparison 3} \\
\hline & Median & IQR & Median & IQR & Median & IQR & Median & IQR & Mean & S.D. & & B-PLS & B-CFO & S-PLS & $\mathrm{S}-\mathrm{CFO}$ & B/PLS-B/CFO & S/PLS-S/CFO \\
\hline $\begin{array}{l}\text { Max flexion moment in } \\
\text { stance }(\mathrm{Nm} / \mathrm{kg})\end{array}$ & -0.42 & 0.18 & -0.47 & 0.19 & -0.54 & 0.19 & -0.50 & 0.28 & -0.35 & 0.14 & & & & & * & & \\
\hline $\begin{array}{l}\text { Max extension moment in } \\
\text { stance }(\mathrm{Nm} / \mathrm{kg})\end{array}$ & 0.17 & 0.15 & 0.26 & 0.30 & 0.29 & 0.31 & 0.25 & 0.24 & 0.23 & 0.18 & $* *$ & $* *$ & & & & & \\
\hline $\begin{array}{l}\text { Max power generation in } \\
\text { stance }(\mathrm{W} / \mathrm{kg})\end{array}$ & 0.66 & 0.36 & 0.99 & 0.54 & 0.88 & 0.27 & 0.83 & 0.26 & 0.77 & 0.52 & * & & & & & & \\
\hline $\begin{array}{l}\text { Max power absorption in } \\
\text { stance }(\mathrm{W} / \mathrm{kg})\end{array}$ & -0.96 & 0.60 & -1.05 & 0.55 & -0.97 & 0.61 & -1.02 & 0.15 & -0.56 & 0.44 & & & & & & & \\
\hline \multicolumn{18}{|l|}{ Hip } \\
\hline $\begin{array}{l}\text { Flexion at initial } \\
\text { contact }\left(^{\circ}\right)\end{array}$ & 40.20 & 10.37 & 41.01 & 8.27 & 42.43 & 10.90 & 43.43 & 9.42 & 34.20 & 6.60 & & $* *$ & $* *$ & & & & \\
\hline $\begin{array}{l}\text { Max extension in } \\
\text { stance }\left({ }^{\circ}\right)\end{array}$ & -11.15 & 5.01 & -9.97 & 10.66 & -11.79 & 6.05 & -12.15 & 6.37 & -10.80 & 6.10 & & & & & & & \\
\hline $\begin{array}{l}\text { Range of sagittal } \\
\text { motion in stance }\left({ }^{\circ}\right)\end{array}$ & 47.38 & 9.61 & 49.82 & 8.79 & 52.61 & 8.14 & 54.17 & 6.39 & 45.20 & 5.20 & * & & & & & & \\
\hline Max flexion in swing $\left({ }^{\circ}\right)$ & 43.52 & 9.67 & 46.31 & 11.74 & 46.73 & 13.93 & 45.71 & 10.49 & 37.00 & 6.10 & & & & & & & \\
\hline $\begin{array}{l}\text { Mean coronal angle in } \\
\text { stance }\left({ }^{\circ}\right)\end{array}$ & 1.21 & 4.50 & 0.06 & 6.28 & 1.28 & 5.33 & 1.74 & 6.70 & 3.90 & 3.50 & & & & & & & \\
\hline $\begin{array}{l}\text { Mean coronal angle in } \\
\text { swing }\left({ }^{\circ}\right)\end{array}$ & -2.70 & 3.96 & -5.13 & 4.02 & -4.35 & 4.26 & -3.15 & 4.10 & -2.77 & 3.10 & ** & & & & $*$ & & \\
\hline $\begin{array}{l}\text { Rotation angle at initial } \\
\text { contact }\left({ }^{\circ}\right)\end{array}$ & -3.83 & 17.73 & -5.87 & 19.56 & -6.51 & 12.61 & -8.11 & 21.76 & 2.28 & 7.80 & & & * & & & & \\
\hline $\begin{array}{l}\text { Rotation angle at the } \\
\text { end of mid-stance }\left(^{\circ}\right)\end{array}$ & 3.70 & 12.78 & 5.23 & 12.44 & 3.87 & 14.76 & 3.76 & 13.14 & 7.70 & 7.70 & & & & $*$ & & & \\
\hline $\begin{array}{l}\text { Rotation angle at } \\
\text { toe-off }\left({ }^{\circ}\right)\end{array}$ & 0.75 & 11.59 & 1.60 & 15.24 & 5.62 & 13.69 & 1.04 & 18.82 & 0.40 & 7.70 & $*$ & $* *$ & $* *$ & $* *$ & & & \\
\hline $\begin{array}{l}\text { Rotation angle at mid- } \\
\text { swing }\left(^{\circ}\right)\end{array}$ & 0.50 & 18.76 & 1.67 & 12.24 & 1.13 & 12.06 & 1.23 & 16.89 & 1.60 & 8.00 & & & & & $*$ & & \\
\hline $\begin{array}{l}\text { Flexion velocity in } \\
\text { swing }(\mathrm{rad} / \mathrm{s})\end{array}$ & 4.18 & 0.93 & 4.36 & 0.51 & 4.69 & 0.72 & 4.48 & 0.83 & 4.00 & 0.51 & & & & & & & \\
\hline $\begin{array}{l}\text { Max abduction moment } \\
\text { in stance }(\mathrm{Nm} / \mathrm{kg})\end{array}$ & 0.64 & 0.18 & 0.66 & 0.33 & 0.74 & 0.28 & 0.67 & 0.14 & 0.54 & 0.33 & & * & & & & * & * \\
\hline $\begin{array}{l}\text { Max extension moment } \\
\text { in stance }(\mathrm{Nm} / \mathrm{kg})\end{array}$ & 0.90 & 0.53 & 1.03 & 0.46 & 1.00 & 0.65 & 1.05 & 0.55 & 0.78 & 0.31 & & & & & & & \\
\hline $\begin{array}{l}\text { Max flexion moment } \\
\text { in stance }(\mathrm{Nm} / \mathrm{kg})\end{array}$ & -0.65 & 0.29 & -0.80 & 0.30 & -0.90 & 0.21 & -0.95 & 0.22 & -0.74 & 0.20 & $*$ & $* *$ & $* *$ & * & $*$ & & \\
\hline $\begin{array}{l}\text { Timing of sagittal } 0 \\
\text { moment in hip (\%) }\end{array}$ & 26.67 & 9.67 & 32.00 & 3.83 & 30.00 & 9.00 & 32.00 & 26.50 & 24.00 & 7.00 & * & * & & & & & \\
\hline $\begin{array}{l}\text { Max power generation } \\
\text { in stance }(\mathrm{H} 1)(\mathrm{W} / \mathrm{kg})\end{array}$ & 0.98 & 0.55 & 1.00 & 0.71 & 1.33 & 0.71 & 1.29 & 0.82 & 0.50 & 0.60 & & & & & & & \\
\hline $\begin{array}{l}\text { Max power absorption } \\
\text { in stance }(\mathrm{H} 2)(\mathrm{W} / \mathrm{kg})\end{array}$ & -0.96 & 0.38 & -1.32 & 2.93 & -1.46 & 0.61 & -1.42 & 0.52 & -0.74 & 0.36 & $* *$ & $* *$ & $* *$ & & & & \\
\hline $\begin{array}{l}\text { Max power generation } \\
\text { at pre swing/toe-off } \\
(\mathrm{H} 3)(\mathrm{W} / \mathrm{kg})\end{array}$ & 0.76 & 0.42 & 0.87 & 0.48 & 0.83 & 0.63 & 0.83 & 0.22 & 0.80 & 0.42 & & & & & & & \\
\hline
\end{tabular}




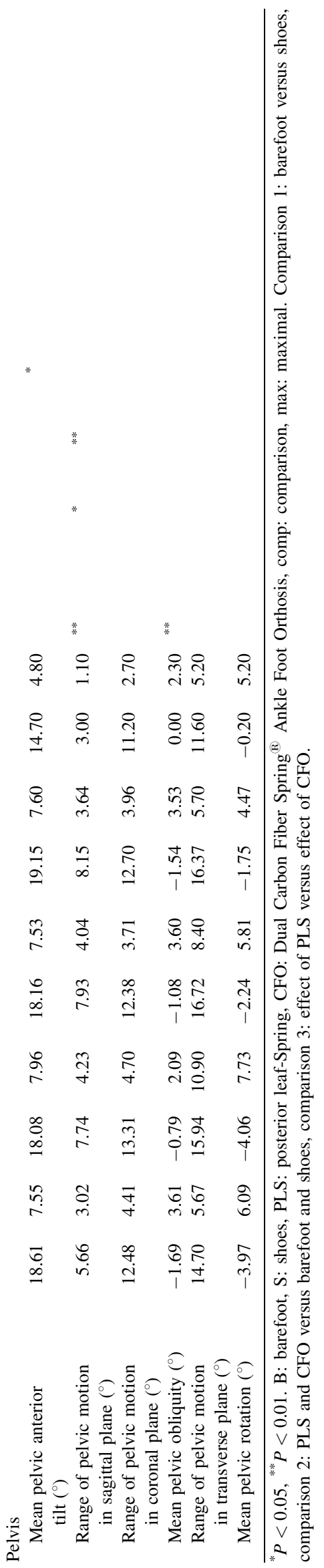

non-parametric statistical analyses were performed. The data of the study were split up into four conditions: 1, barefoot; 2, shoes; 3, PLS; 4, CFO. In each condition, the median and interquartile range (IQR) for the 52 parameters were calculated for the total group. Mean continuous traces of kinematic and kinetic data per gait cycle were also calculated for the four conditions. Discrete values allowed statistical evaluation of the significance of observed differences between the conditions. Further data analysis included three types of comparisons (Fig. 3). First, a Wilcoxon signed rank test was performed determining statistical significant differences between barefoot and shoes (Fig. 3a). Secondly, for both the PLS and the CFO, a comparison with barefoot and shoe condition respectively was conducted through another Wilcoxon signed rank test, quantifying the effects of both orthoses (Fig. 3b). Finally, the effects of the PLS and of the CFO were mutually compared (Wilcoxon signed rank test on difference scores between AFO condition and control condition) (Fig. 3c). A Bonferroni correction was applied to reduce the likelihood of obtaining false-positive results because of the repeated Wilcoxon signed rank tests. The critical $P$-value was defined as 0.01. All statistical procedures were performed with the SAS system (SAS Institute Inc., SAS Campus Dr, Cary, NC 27513).

\section{Results}

An overview of the median and interquartile range (IQR) for the four different walking conditions, along with the mean values and standard deviation (S.D.) of the normal control group, is presented in Table 1. The results of the three types of comparisons ( $P$-values of the Wilcoxon signed rank tests) are also included in Table 1. Averaged data for ankle power generation in pre-swing and averaged continues traces for ankle motion and hip power are illustrated in Figs. 4 and 5.

\subsection{Comparison 1: shoes versus barefoot}

The only significantly improved spatio-temporal parameter in shoes compared to barefoot was cadence $(P<0.01)$. At ankle level, significant changes in walking pattern were observed with increased range of motion and angular velocity during push-off $(P<0.01)$ (Fig. 5a). Shoes also significantly influenced knee motion, with increased knee shock absorption, knee flexion in swing and maximal knee extension moment in stance. Finally, mean coronal hip angle in swing, mean pelvic obliquity, and maximal hip power absorption in stance were significantly increased in shoes when compared to barefoot $(P<0.01)$. Apart from knee shock absorption and mean pelvic obliquity, all significantly changed knee, hip, and pelvis parameters indicated more pronounced deviations in shoes compared to barefoot, usually indicating an over-correction. 
(a)
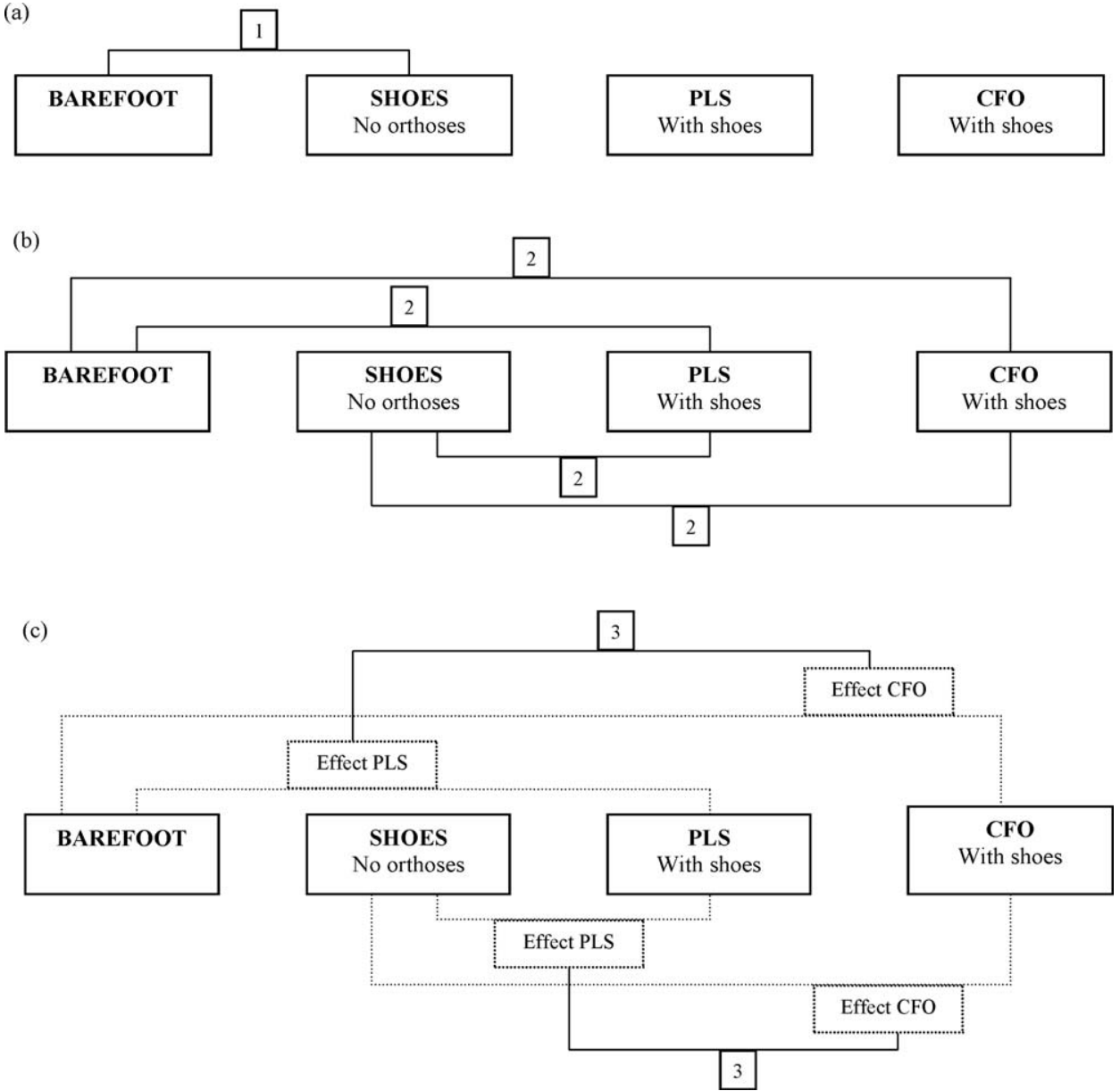

Fig. 3. Comparisons of walking conditions: (a) Comparison 1: barefoot versus shoes; (b) Comparison 2: PLS and CFO versus barefoot and shoes and (c) Comparison 3: effect of PLS versus effect of CFO, with barefoot and shoes as a reference (based on differences scores between AFO condition and barefoot or shoe condition).

\subsection{Comparison 2: PLS and CFO versus barefoot and shoes}

Walking velocity and step length increased in both orthotic conditions when compared to barefoot (PLS: $P<0.01$, CFO: $P<0.05$ ), but neither was significantly different when compared to walking in shoes.

When comparing walking with orthoses to barefoot, all children demonstrated an improved first and second ankle rocker and foot clearance in swing $(P<0.01)$ (Fig. 5a).

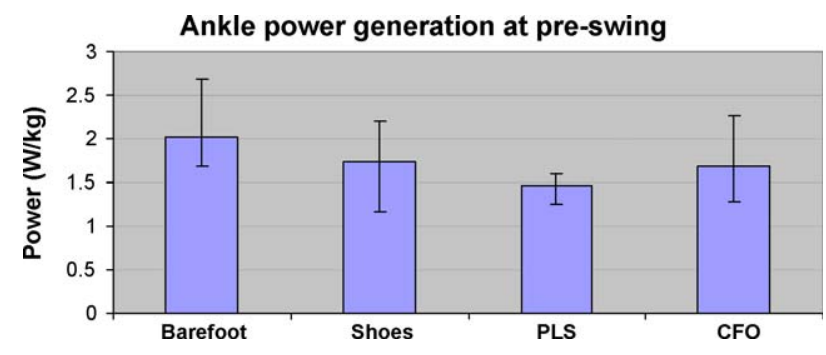

Fig. 4. Median, P25 and P75 of ankle power generation at pre-swing for the four walking conditions.
Although plantarflexion moment at push-off increased in both orthoses $(P<0.01)$, ankle range of motion during push-off, power generation in pre-swing, and ankle velocity at toe-off deteriorated $(P<0.01)$. When compared to shoes, neither timing of maximal dorsiflexion in stance, nor power generation in pre-swing varied significantly in orthoses. However, ankle moment at loading response reached significance for both orthoses $(P<0.01)$. Ankle range of motion during push-off was still worse in orthoses compared to shoe walking $(P<0.01)$. In $\mathrm{CFO}$ maximal dorsiflexion in stance returned to normal, but this improvement did not reach the level of the critical $P$-value.

At knee level children also seemed to benefit significantly from wearing orthoses compared to barefoot. Both orthoses improved knee shock absorption and maximal knee flexion in stance $(P<0.01)$, and tended to change maximal knee flexion and timing of peak flexion in swing $(P<0.05)$. Using shoe walking as a reference, the influence of both orthoses on maximal knee flexion and timing of peak knee flexion in swing disappeared, but maximal knee flexion in stance was still significantly higher $(P<0.01)$. The PLS caused mild knee hyperextension $(P<0.05)$, but the 
(a) Ankle Dorsi/Plantar

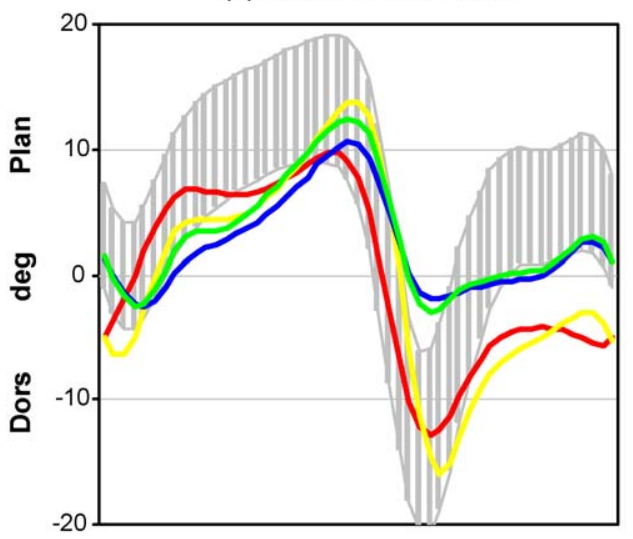

(b) Hip Power

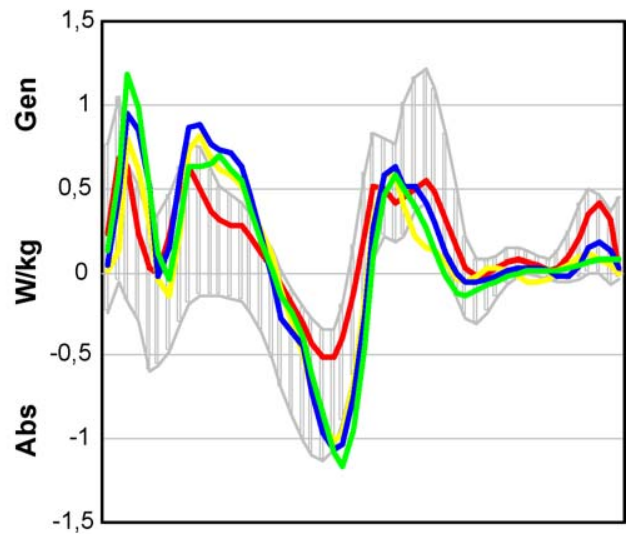

Fig. 5. Averaged continuous traces for ankle motion (a) and hip power (b) for four walking conditions (red $=$ barefoot, yellow $=$ shoes, blue $=$ PLS and green $=\mathrm{CFO})(N=15)$ and for a group of normal children of $3-11$ years of age (shadow $= \pm 1$ S.D. $)(N=51)$.

increase in maximal knee flexion moment was not found to be statistically significant.

Both PLS and CFO, created a significantly improved hip flexion moment in stance, when compared to barefoot. Hip flexion at initial contact, hip rotation angle at toe-off, as well as maximal hip power absorption in stance, deviated significantly more from normal data in both orthotic conditions compared to barefoot $(P<0.01)$. When compared to shoes, only the PLS showed a significant effect on hip rotation angle at toe-off $(P<0.01)$. Both orthoses clearly increased hip power generation in stance beyond normal limits, but these changes did not reach the level of the critical $P$-value (Fig. 5b).

Orthoses led to a further increase in the already high range of pelvic motion in the sagittal plane (PLS: $P<0.05$, CFO: $P<0.01$ ) when compared to barefoot, however this sagittal range of motion was too large for orthoses as well as for barefoot.

\subsection{Comparison 3: effect of PLS versus effect of $C F O$ (with both barefoot and shoes as a reference)}

Comparing the effect of PLS and CFO, a few parameters differed significantly. The CFO performed better for ankle range of motion during push-off, power generation in preswing (Fig. 4) and ankle angular velocity $(P<0.01)$, whereas the PLS produced a slightly more normal ankle moment and power absorption at loading response $(P<0.05)$.

Although both orthoses led to increased knee flexion velocity at toe off $(P<0.05)$, the effect of the PLS was significantly higher compared to the CFO $(P<0.01)$. The PLS also led to reduced knee flexion at initial contact and a slightly hyperextended knee in stance $(P<0.05)$, which was not observed in the CFO.

The PLS was associated with further increase in maximal hip abduction moment in stance compared to the CFO
$(P<0.05)$. At pelvic level, no differences between the effect of both orthoses were identified.

\section{Discussion}

\subsection{Shoes versus barefoot}

AFOs are usually applied in combination with footwear. Shoes, however, may also change the gait pattern, leading to false interpretations. A thorough evaluation of an AFO should therefore include a shoes-AFO and a barefoot-shoes comparison. Churchill et al. already pointed this out in their study when they compared five post-stroke patients with hemiplegia when walking barefoot, with shoes alone, and with AFOs combined with shoes. Spatio-temporal parameters were recorded during gait analysis. Stride length and swing velocity (stride length/swing time) turned out to be significantly increased in shoes when compared to barefoot. Churchill concluded that comparisons made between AFO and barefoot might underestimate the relative contribution of existing footwear [18]. However, the sample size of this study was limited and only spatio-temporal parameters were registered. Oeffinger et al. also conducted a study comparing shoe and barefoot walking. Only stride length was reported to be significantly increased in shoes. However, due to tight standard deviations, this difference was not considered clinically relevant and consequently the conclusion was that an additional assessment wearing shoes was not necessary [17].

In this study, both shoe and barefoot walking trials were used, to exclude shoes as a possible confounding factor enhancing the effects of the AFO. Cadence, ankle range of motion, ankle velocity, and knee shock absorption significantly improved. However, knee flexion in stance and swing, maximal knee extension moment in stance, ankle power generation at push-off, and maximal hip power 
absorption in stance worsened when walking with shoes compared to barefoot. These differences clearly indicate that shoes influence the gait pattern and the effects of AFOs should always be weighed against the influence of shoes.

\subsection{Orthoses and third ankle rocker}

This study aimed at comparing push-off in two different types of AFOs. The newer design CFO (Dual Carbon Fibre Spring $\mathrm{AFO}^{\mathbb{R}}$ ) was designed to increase range of motion and improve kinetics in the crucial and final phase of stance, compared to the conventional PLS.

In general, the existing literature indicates that applying an AFO can improve the gait pattern, at the expense of reducing ankle range of motion and power generation at push-off $[1,3,5-$ 8]. In this study, push-off was also found to decrease with both types of orthoses compared to barefoot, confirming the existing literature. However, when compared to the PLS, the CFO displayed increased push-off. The CFO produced a significantly greater ankle range of motion, angular velocity and power generation at pre-swing, thereby significantly improving third ankle rocker when compared to the PLS. Where the PLS still significantly decreased ankle power generation during push-off when compared to barefoot, the decrease observed in the CFO did not reach significance anymore (Fig. 4). A recent study by Wolf et al. using carbon spring orthosis for patients with myelomeningocele and poliomyelitis offers a further confirmation of the abovedescribed results. Improved push-off was observed as the spring was loaded in loading response and midstance, resulting in a forward push of the tibia and an increased push-off [26].

Interestingly, the hip power generation in stance slightly decreased in the CFO compared to the PLS. This might further support our hypothesis that the CFO improves pushoff at the ankle when compared to the PLS, leading to a decreased need for power generation at the hip. However, it should be noted that differences in power might also have been caused by the small differences in walking velocity.

\subsection{Other gait parameters}

The results of this study support the findings of previous studies indicating that orthoses improve spatio-temporal parameters [3,7,11]. All orthoses improved the walking velocity with decreased cadence and increased step length. Improved stability in stance was observed as prolonged single support phase in the gait cycle. However, when these parameters were compared to those during shoe walking, none of the observed improvements was significant. This indicates that it is the combination of shoes and orthoses that is crucial in improving spatio-temporal parameters.

As expected and extensively reported in literature, all orthoses enabled children to achieve heel initial contact thereby normalizing first ankle rocker [1,3,5-8]. Although no significant differences could be found between the orthoses, more dorsiflexion was observed with the CFO.
Previous studies reported benefits from increased dorsiflexion in stance as this allowed the calf muscles to stretch and generate improved push-off [1,5,7]. Foot clearance improved as the orthoses held the ankle in dorsiflexion in swing. Further improvement of foot clearance in this study probably also occurred through improved knee movement in swing, resulting from increased distal stability through the application of orthoses [27-29]. In this study, the improved distal stability was reflected through increased knee flexion and angular velocity and an improved timing of peak knee flexion in swing. On the other hand, both CFO and PLS created a maximal knee flexion in swing that was slightly above normal ranges.

Brunner et al. previously reported that orthoses improve knee shock absorption and this was confirmed in the present study [7]. However, when applying shoes only, we observed increased shock absorption, which decreased slightly with the orthoses. Therefore, it may be the shoes and not the orthoses that lead to knee shock absorption improvement.

Concerning knee extension in stance, Buckon et al. reported HAFO, PLS, and SAFO to decrease knee hyperextension by preventing ankle plantarflexion. The HAFO was found to be the most effective [3]. These results could not be fully supported by this study. The CFO did not influence knee hyperextension, whereas the PLS slightly increased knee hyperextension. Consequently, the knee flexion moment slightly increased as well, reflecting the importance of strict tuning of the AFOs.

At the hip, flexion at initial contact increased significantly above normal limits for all orthoses when compared to barefoot. Maximal hip extension moment was also greater in all orthoses, along with a later timing in the gait cycle of zero hip moment when compared to barefoot. All these findings around the hip can be explained through the larger step length observed in orthoses. These changes were slightly more pronounced in the CFO than in the PLS, which reflects the flexibility of the orthoses.

In conclusion, both orthoses successfully improved gait patterns, but push-off at the ankle significantly improved when the CFO was compared to the PLS. The results of this study further support the findings of previous studies indicating that orthoses improve specific gait parameters compared to barefoot walking. However, compared to shoes, not all improvements were significant.

\section{Acknowledgements}

The authors wish to express their thanks to the multidisciplinary team of the Clinical Motion Analysis Laboratory at the University Hospital of Pellenberg for their invaluable assistance and support, Jozef Nijs for his statistical assistance, Kim Daniels for her contribution to the preparation of Tables and Figures and all the children and their families for their enthusiastic participation in this study. This research was supported by an unrestricted 
educational grant from CTO (Centre of Technical Orthopaedics, Belgium).

\section{References}

[1] Woo R. Spasticity: orthopedic perspective. J Child Neurol 2001;16: 47-53.

[2] Gage JR, Quanbeck DS. Orthotics and mobility aids in cerebral palsy. In: Gage JR, editor. The treatment of gait problems in cerebral palsy. London: Mac Keith Press; 2004. p. 273-85.

[3] Buckon CE, Thomas SS, Jakobson-Huston S, Sussman M, Aiona M. Comparison of three ankle-foot orthosis configurations for children with spastic hemiplegia. Dev Med Child Neurol 2001;43:371-8.

[4] Flett PJ. Rehabilitation of spasticity and related problems in childhood cerebral palsy. J Paediatr Child Health 2003;39:6-14.

[5] Rethlefsen S, Kay R, Dennis S, Forstein M, Tolo V. The effects of fixed and articulated ankle-foot orthoses on gait patterns in subjects with cerebral palsy. J Pediatr Orthop 1999;19:470-4.

[6] Romkes J, Brunner R. Comparison of a dynamic and a hinged anklefoot orthosis by gait analysis in patients with hemiplegic cerebral palsy. Gait Posture 2002;15:18-24.

[7] Brunner R, Meier G, Ruepp T. Comparison of a stiff and a spring-type ankle-foot orthosis to improve gait in spastic hemiplegic children. J Pediatr Orthop 1998;18:719-26.

[8] Ounpuu S, Bell KJ, Davis 3rd RB, DeLuca PA. An evaluation of the posterior leaf-spring orthosis using joint kinematics and kinetics. J Pediatr Orthop 1996;16:378-84.

[9] Morris C. A review of the efficacy of lower-limb orthoses used for cerebral palsy. Dev Med Child Neurol 2002;44:205-11.

[10] White H, Jenkins J, Neace WP, Tylkowski C, Walker J. Clinically prescribed orthoses demonstrate an increase in velocity in children with cerebral palsy: a retrospective study. Dev Med Child Neurol 2002;44:227-32.

[11] Radtka SA, Skinner SR, Dixon DM, Johanson ME. A comparison of gait with solid, dynamic, and no ankle-foot orthoses in children with spastic cerebral palsy. Phys Ther 1997;77:395-409.

[12] Middleton EA, Hurley GRB, McIlwain JS. The role of rigid and hinged polypropylene ankle-foot orthoses in the management of cerebral palsy: a case study. Prosthet Orthot Int 1988;12: 129-35.

[13] Hainsworth F, Harrison MJ, Sheldon TA, Roussounis SH. A preliminary evaluation of ankle orthoses in the management of children with cerebral palsy. Dev Med Child Neurol 1997;39:243-7.
[14] Radtka SA, Skinner SR, Elise Johanson M. A comparison of gait with solid and hinged ankle-foot orthoses in children with spastic diplegic cerebral palsy. Gait Posture 2005;21:303-10.

[15] Dursun E, Dursun N, Alican D. Ankle-foot orthoses: effect on gait in children with cerebral palsy. Disabil Rehabil 2002;24:345-7.

[16] Tyson SF, Thornton HA. The effect of a hinged ankle foot orthosis on hemiplegic gait: objective measures and users' opinions. Clin Rehabil 2001;15:53-8.

[17] Oeffinger D, Brauch B, Cranfill S, Hisle C, Wynn C, Hicks R, Augsburger S. Comparison of gait with and without shoes in children. Gait Posture 1999;9:95-100.

[18] Churchill AJ, Halligan PW, Wade DT. Relative contribution of footwear to the efficacy of ankle-foot orthoses. Clin Rehabil 2003;17:5537.

[19] Gage JR. Specific problems of the hips, knees and ankles. In: Gage JR, editor. The treatment of gait problems in cerebral palsy. London: Mac Keith Press; 2004. p. 205-16.

[20] Winters Jr TF, Gage JR, Hicks R. Gait patterns in spastic hemiplegia in children and young adults. J Bone Joint Surg Am 1987;69:437-41.

[21] Gage JR, Stout J, Van Heest AE. Hemiplegia: pathology and treatment. In: Gage JR, editor. The treatment of gait problems in cerebral palsy. Mac Keith Press: London; 2004. p. 314-44.

[22] Inman VT, Ralston HJ, Todd F. Human walking Baltimore: Williams \& Wilkens; 1991

[23] Gage JR. Gait analysis in cerebral palsy London: Mac Keith Press; 1991. p. 101-131.

[24] Perry J. Gait analysis: normal and pathological function Thorofare: SLACK incorporated; 1992.

[25] Desloovere K, Molenaers G, Jonkers I, De Cat J, De Borre L, Nijs J, Eyssen M, Pauwels P, De Cock P. A randomised study of botulinum toxin A \& casting in the ambulant child with cerebral palsy using objective measures. Eur J Neurol 2001;8:75-87.

[26] Wolf S, Knie I, Rettig O, Fuchs A, Döderlein L. Carbon spring AFOs for active push-off. Abstract of 10th GCMAS meeting April 6-9 2005, Portland.

[27] Damiano DL. Reviewing muscle cocontraction: is it a developmental, pathological or motor control issue? Phys Occup Ther Pediatr 1993;12:3-20.

[28] Damiano DL, Martellotta TL, Sullivan DJ, Granata KP, Abel MF. Muscle force production and functional performance in spastic cerebral palsy: relationship of cocontraction. Arch Phys Med Rehabil 2000;81:895-900.

[29] Farmer SE. Key factors in the development of lower limb co-ordination: implications for the acquisition of walking in children with cerebral palsy. Dishabil Rehabil 2003;25:807-16. 